\title{
ARTICLE OPEN \\ Chitosan-capped gold nanoparticles for indicating temperature abuse in frozen stored products
}

\author{
Chitradurga Obaiah Mohan (iD)', S. Gunasekaran ${ }^{2}$ and C. N. Ravishankar ${ }^{3}$
}

The present study aimed to optimize the conditions for the synthesis of gold nanoparticles (AuNP) using chitosan and to assess its effectiveness as temperature threshold indication for frozen storage conditions. Chitosan concentration of $0.25 \%$ and temperature of $90^{\circ} \mathrm{C}$ for $15 \mathrm{~min}$ was optimum for synthesizing AuNP. The maximum absorbance $\left(\lambda_{\max }\right)$ was observed at 530 and $540 \mathrm{~nm}$ for $0.125 \%$ and $0.25 \%$ chitosan, respectively, indicating shifting of peak toward longer wavelengths (red shift) with increasing chitosan concentration indicating larger AuNPs. A prominent absorption peak at $1367 \mathrm{~cm}^{-1}$ by Fourier transform-infrared (FTIR) spectrum corresponding to $\mathrm{C}-\mathrm{C}$ stretching of the glucosamine group of chitosan indicates the chitosan capping on the AuNP. Higher peak intensity and a peak shift toward shorter wavelength were observed for AuNPs exposed to frozen temperature abused conditions. Distinctly clear visible color variation from cherry red to gray indicates its application as temperature abuse indicator in frozen products.

npj Science of Food (2019)3:2; https://doi.org/10.1038/s41538-019-0034-z

\section{INTRODUCTION}

Temperature is the most crucial factor affecting the quality by influencing the kinetics of physical, chemical, and microbial spoilage in perishable food commodities as well as pharmaceutical products. The storage temperature of the temperaturesensitive products like chilled, refrigerated and frozen stored food, pharmaceutical, and biological products is monitored strictly to ensure that the product remains within the accepted threshold range and to ensure conformance with product release specification. At present, the temperature of frozen products in the foodprocessing establishments is monitored using temperature recorders. There is no mechanism for monitoring the temperature of foods during transportation and distribution and in retail stores. A visible temperature abuse indicator will be useful for maintaining the proper storage conditions at all the stages. This can be achieved by nanotechnology by developing biosensors like thermal history indicator (THI) that provides very useful information on temperature history. THI is an important type of intelligent packaging. It consists of a simple device that can be attached to the packaging containing food or pharmaceutical products to indicate its storage temperature history and thereby quality and safety of the products. Three basic types of THIs like critical temperature indicators, partial history indicators, and full history indicators are available in the market, ${ }^{1}$ which are either diffusion-, enzymatic-, or polymer-based systems. Development of THIs using metal nanoparticles is gaining popularity among the research community, and among the metal nanoparticles, gold nanoparticles (AuNPs) have attracted considerable attention due to its unique therapeutic activity, optical behavior, inert, and nontoxic nature. The AuNPs can be prepared by employing supercritical fluid technology, physical, chemical, and biological methods. Biological methods for nanoparticle synthesis using microorganisms, enzymes, vitamins, sugar, and biodegradable polymers of plant or animal origin have been suggested as possible ecofriendly alternatives to chemical and physical methods. ${ }^{2,3}$

Using chitosan, a derivative of chitin, which is one of the most abundant natural biodegradable polysaccharide extracted from crustacean waste, for nanoparticle synthesis can be advantageous over other biological processes as it avoids the elaborate process and can be easily scaled up. Chitin is the second most abundantly available natural polymer after cellulose, ${ }^{4}$ which can be extracted from crab, shrimps shell waste, and the bone plates of squid and cuttlefish. ${ }^{5}$ It is not soluble in dilute acids, whereas chitosan, which is a deacetylated form of chitin, is soluble in dilute acids. Use of chitosan for fish preservation ${ }^{4,6-8}$ and for the synthesis of AuNP is studied by many researchers. ${ }^{9-13}$ Studies on THI using biomolecules alginate ${ }^{14}$ and gelatin ${ }^{15}$ have been reported. However, there is no report on the THI using chitosan. Capping AuNPs with various chemicals and natural compounds results in alterations in the basic properties of AuNPs. Gold nanoparticles obtained by capping with chitosan can be used as temperature abuse indicator as the AuNPs change its color and intensity of the color with fluctuation in storage temperature and its duration. This variation in color and color intensity is mainly due to the alteration in size and shape of chitosan-capped AuNPs, which can be used for the development of sensors. Although many researchers have demonstrated the synthesis of AuNPs using chitosan, there are very limited reports on the use of chitosan-capped AuNPs for sensor applications. Hence, the present study was undertaken with the objective of optimizing the process conditions for synthesizing the chitosan-capped AuNPs, to characterize and to evaluate its application as temperature abuse indicator for frozen storage conditions.

\footnotetext{
${ }^{1}$ Fish Processing Division, ICAR-Central Institute of Fisheries Technology (Indian Council of Agricultural Research), Ministry of Agriculture \& Farmers Welfare, Govt. of India,

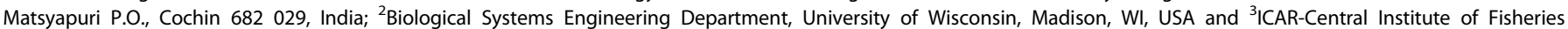
Technology (Indian Council of Agricultural Research), Ministry of Agriculture \& Farmers Welfare, Govt. of India, Matsyapuri P.0., Cochin 682 029, India Correspondence: Chitradurga Obaiah Mohan (comohan@gmail.com)
}

Received: 14 June 2018 Accepted: 10 January 2019

Published online: 31 January 2019 


\section{RESULTS AND DISCUSSION}

Properties of chitosan

Chitosan can be used as a reducing agent to obtain the gold nanoparticles due to its electronegativity property. It can also act as an electrostatic stabilizer as it is a polyelectrolyte, which would render dual advantage by providing sufficient charge through the amino groups, which will aid in the subsequent attachment of the biomolecules, as well as render optimum stability and subsequently help to improve the uptake of the nanoparticles. Quality characteristics of chitosan used in the present study are summarized in Table 1 . The chitosan had a slightly yellowish creamy white color. The moisture content was less than $8 \%$, and protein and ash content were $0.92 \%$ and $1.16 \%$, respectively. The degree of deacetylation, which is one of the important properties of the chitosan, ${ }^{16}$ deciding its application, was found to be $81.34 \%$. The results of the viscosity indicated that the chitosan used in the study had low viscosity $(79 \mathrm{cP})$ and the $\mathrm{pH}$ of chitosan solution (in acetic acid) was 3.94 .

Optimization of synthesis condition for chitosan-capped AuNPs Optimization of the concentration of chitosan, as well as time and temperature assumes importance as it varies with biomolecules and chemicals. For optimization of chitosan concentration, heating temperature and duration was kept constant, i.e., $90^{\circ} \mathrm{C}$ for $15 \mathrm{~min}$ based on available literature for different biomolecules. $^{14,15,17}$ Upon addition of $\mathrm{HAuCl}_{4} \cdot 3 \mathrm{H}_{2} \mathrm{O}$ to the clear solution of chitosan, the solution turned into bright yellow color. For solutions with 0.125 and $0.25 \%$ chitosan, the color changed from bright yellow to light yellow, colorless, suggesting the reduction of $\mathrm{Au}$ ions into Au atoms. Upon continued heating, the solution started to turn into light pink indicating the formation of AuNPs. Further heating resulted in the formation of dark cherry red color, indicating the formation of chitosan-capped gold nanoparticles. This clearly indicates the formation of AuNPs in the concentrations of 0.125 and $0.25 \%$ chitosan. However, the color was highly intensive for the solution with $0.25 \%$ of chitosan, compared to $0.125 \%$ of chitosan, which is supported by UV-visible spectral observation. For the lower concentration of chitosan $(0.0625 \%)$, the bright yellow color persisted for $10 \mathrm{~min}$, which slowly changed to light yellow color by the end of $15 \mathrm{~min}$ of heating time. This indicates that the lower concentration of chitosan was not effective for the formation of AuNPs. The $\lambda_{\max }$ for chitosancapped AuNPs was observed at 530 and $540 \mathrm{~nm}$ for $0.125 \%$ and $0.25 \%$ chitosan, respectively, and for lower chitosan concentration $(0.0625 \%)$, a prominent peak was not observed (Fig. 1a). This indicates that more AuNPs were synthesized in $0.25 \%$ chitosan, compared to other concentrations at the same heating conditions, and hence this concentration was used for further optimization of heating temperature and time. UV-Visible spectra of chitosancapped AuNPs exposed to different heating times are shown in Fig. 1b. Lower heating time of 5 and $10 \mathrm{~min}$ did not show any peak. Heating time of only $15 \mathrm{~min}$ resulted in a prominent peak indicating its suitability. Among three heating temperatures

\begin{tabular}{ll} 
Table 1. & Properties of chitosan (mean \pm standard deviation, $n=5)$ \\
\hline Attributes & Results \\
\hline Appearance & Slightly yellowish \\
Moisture (\%) & $7.95 \pm 0.21$ \\
Protein (\%) & $0.92 \pm 0.13$ \\
Ash (\%) & $1.16 \pm 0.11$ \\
Degree of deacetylation (\%) & $81.34 \pm 1.34$ \\
Viscosity (cP) & $78.96 \pm 1.06$ \\
pH & $3.94 \pm 0.05$ \\
\hline
\end{tabular}

studied $\left(70,80\right.$, and $\left.90^{\circ} \mathrm{C}\right)$, higher heating temperature, i.e., $90^{\circ} \mathrm{C}$ for $15 \mathrm{~min}$ resulted in bright cherry red-colored solution indicating the formation of chitosan-stabilized AuNPs (results not shown). The heating temperature of $80^{\circ} \mathrm{C}$ resulted in bright yellow-colored solution, whereas heating at $70^{\circ} \mathrm{C}$ resulted in light yellow color upon heating for $15 \mathrm{~min}$. At both the lower temperatures, the solution did not turn to cherry red color, indicating that these lower heating temperatures for 15 min were not sufficient for the synthesis of AuNPs. Chitosan concentration of $0.25 \%(\mathrm{w} / \mathrm{v})$, heating temperature of $90^{\circ} \mathrm{C}$ for $15 \mathrm{~min}$ was chosen as optimal conditions for the preparation of chitosancapped AuNPs, as indicated by the intense cherry red color. Wang et al. ${ }^{15}$ also reported heating temperature of $90^{\circ} \mathrm{C}$ for $15 \mathrm{~min}$ as the optimum condition for gelatin-based AuNPs to be used as THI. The chitosan concentration was further optimized using chitosan concentrations of $0.2,0.25$, and $0.3 \%(\mathrm{w} / \mathrm{v})$ and characterized as above (results not shown). Based on the spectrophotometric characteristics and visible color changes, chitosan concentration of $0.25 \%$ was found optimum.

\section{Characterization of chitosan-capped AuNPs}

The synthesized AuNPs were characterized by UV-Visible spectroscopy, which has proven to be a very useful method for the detection of prepared metallic nanoparticles. In UV-Vis spectra, the AuNPs exhibit a localized surface plasmon resonance band at around $526 \mathrm{~nm}$ due to collective oscillations of the electron at the surface of the nanoparticles that is correlated with the electromagnetic field of the incoming light. In the present study, $\lambda_{\max }$ was observed at 530 and $540 \mathrm{~nm}$ for $0.125 \%$ and $0.25 \%$ chitosan, respectively, indicating a shift of peak to the right (red shift) (Fig. 1a). This could be due to the formation of AuNPs of various shapes, size, or concentration dependencies. In $0.0625 \%$ chitosan solution heated at $90^{\circ} \mathrm{C}$ for $15 \mathrm{~min}$, the peak could not be observed indicating the absence of AuNPs. The concentration of chitosan affected the size and zeta potential of AuNPs (Table 2). The size of the chitosan-capped AuNPs was $30.6 \mathrm{~nm}$ for $0.25 \%$ chitosan, compared to 59.8 and $175.6 \mathrm{~nm}$ for $0.125 \%$ and $0.0625 \%$ chitosan, respectively. The AuNPs could dissociate due to heating to form smaller particles stabilized by the amine groups on the chitosan, leading to the formation of chitosan-capped stable AuNPs. Although heating time of $15 \mathrm{~min}$ was maintained for all the concentrations of chitosan, reduction of Au ions into Au atoms was faster in $0.25 \%$ chitosan. The smallest particle size obtained for $0.25 \%$ chitosan solution could be due to the shorter reduction time and subsequent heating compared to other samples. Particle sizes of 7,7-35, and $115 \mathrm{~nm}$ have been reported for chitosancapped gold nanoparticles prepared using different grades of chitosan under various conditions. ${ }^{12,13,18}$ Polydispersity varies between 0 and 1 , wherein values between 0 and 0.08 are considered as a nearly monodisperse sample, values between 0.08 and 0.7 are mid-range values, and $0.7-1.0$ indicate a very broad distribution of particle size. In the case of nanoparticles, polydispersity below 0.3 is desirable and values more than 0.3 indicate polydispersity. In the present study, polydispersity varied between 0.209 and 0.247 among the different concentrations of chitosan AuNPs that indicates good dispersion of the nanoparticles. The zeta potential is the measure of surface charge of nanoparticles and it indicates the stability of the nanoparticles in the suspension system. The zeta potential was the least for $0.25 \%$ chitosan-capped AuNPs (51 mV) and increased with the decrease in the chitosan concentration $(58.5$ and $64.2 \mathrm{mV}$ for $0.125 \%$ and $0.0625 \%$ chitosan-capped AuNPs, respectively). Zeta potential observed in the present study is similar to the one reported for gold nanoparticles prepared using $0.1 \%$ chitosan solution. ${ }^{13}$

To characterize the chitosan-capped AuNPs, the functional groups and the corresponding absorption peaks of pure chitosan and chitosan-capped AuNPs were characterized using FTIR spectra 
a

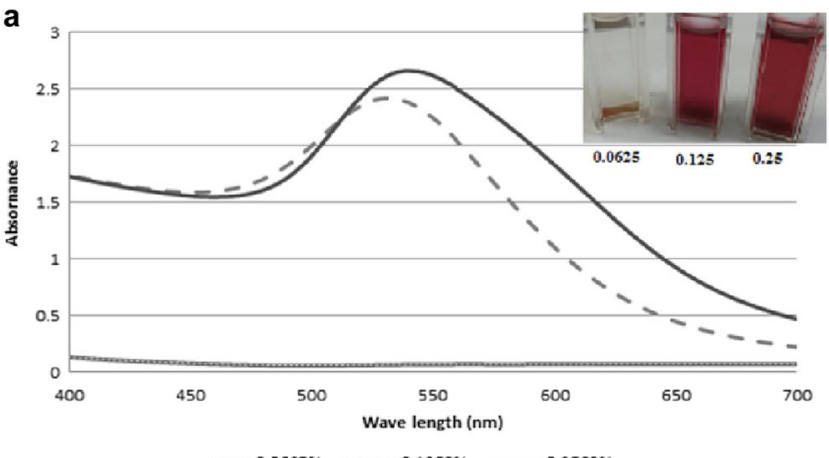

b

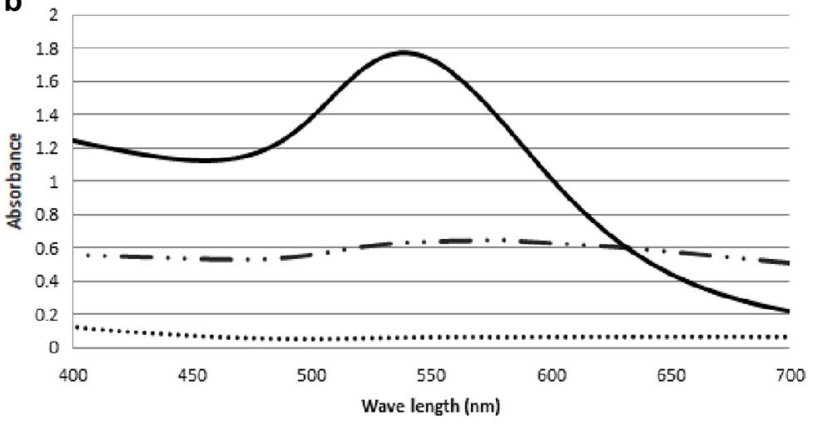

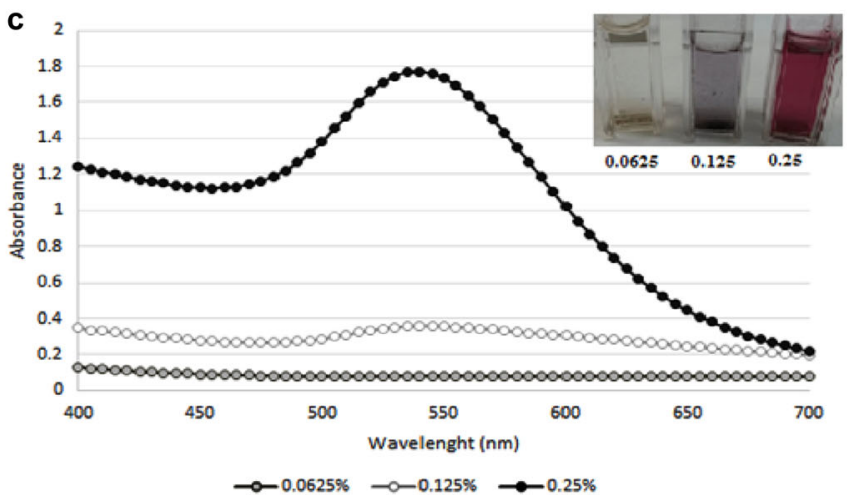

Fig. 1 Influence of chitosan concentration $(0.0625,0.125$, and $0.25 \%)$, heating time, and frozen storage on the UV-Visible spectra and visible color (inset) of chitosan-capped gold nanoparticles

Table 2. Particle size and zeta potential of chitosan gold nanoparticles (mean \pm standard deviation, $n=10$ )

\begin{tabular}{llll}
\hline Parameters & $\begin{array}{l}\text { Chitosan } \\
(0.0625 \%)\end{array}$ & $\begin{array}{l}\text { Chitosan } \\
(0.125 \%)\end{array}$ & $\begin{array}{l}\text { Chitosan } \\
(0.25 \%)\end{array}$ \\
\hline $\begin{array}{l}\text { Effective } \\
\text { diameter (nm) }\end{array}$ & $175.6 \pm 1.28^{\mathrm{a}}$ & $59.8 \pm 1.49^{\mathrm{b}}$ & $30.6 \pm 1.17^{\mathrm{c}}$ \\
$\begin{array}{l}\text { Polydispersity } \\
\begin{array}{l}\text { Zeta potential } \\
(\mathrm{mV})\end{array}\end{array}$ & $0.233 \pm 0.01^{\mathrm{a}}$ & $0.209 \pm 0.01^{\mathrm{b}}$ & $0.247 \pm 0.02^{\mathrm{a}}$ \\
\hline $\begin{array}{l}\mathrm{a}, \mathrm{b}, \mathrm{c} \text { Mean values in } \\
\text { different }(P<0.05)\end{array}$ & $64.24 \pm 2.78^{\mathrm{b}}$ & $58.58 \pm 3.08^{\mathrm{a}}$ & $51.0 \pm 2.18^{\mathrm{a}}$ \\
\hline
\end{tabular}

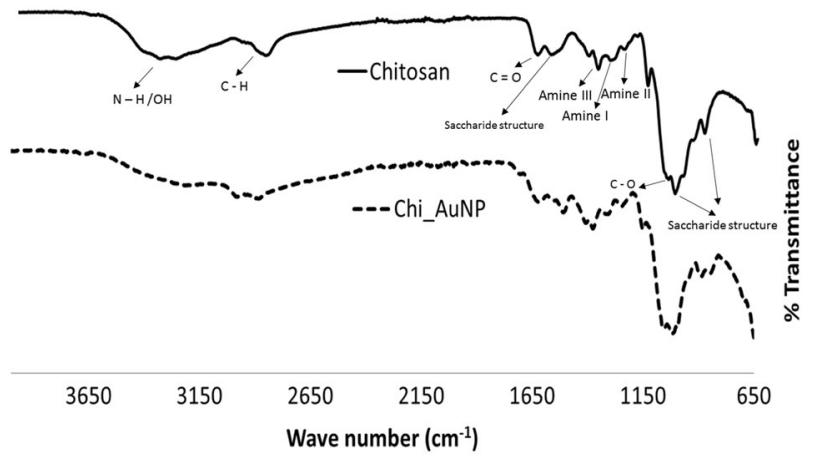

Fig. 2 Fourier transform-infrared spectra of pure chitosan (straight line) and chitosan-capped AuNP (dashed line)
(Fig. 2). FTIR spectra of pure chitosan helped in characterizing the starting material fully and it showed bands at 3357, 3271, 2856, 1639,1579 , and $1367 \mathrm{~cm}^{-1}$. The spectrum of pure chitosan exhibited a broad band between 3357 and $3271 \mathrm{~cm}^{-1}$ due to the stretching vibrations of $\mathrm{O}-\mathrm{H}$ or $\mathrm{N}-\mathrm{H}$ groups. The peak at $2856 \mathrm{~cm}^{-1}$ is attributed to stretching of $\mathrm{C}-\mathrm{H}$ groups. The band located at $1639 \mathrm{~cm}^{-1}$ is related to the vibrations of carbonyl bonds $(\mathrm{C}=\mathrm{O})$ (amide $\mathrm{I})$ of $\mathrm{O}=\mathrm{C}-\mathrm{NHR}$, while the absorption peak at $1579 \mathrm{~cm}^{-1}$ is related to the bending of $\mathrm{N}-\mathrm{H}$ bonds (amide II) $\left(\mathrm{NH}_{2}\right){ }^{19}$ The band at $1408 \mathrm{~cm}^{-1}$ is due to $\mathrm{CH}_{3}$ wagging. ${ }^{20} \mathrm{~A}$ prominent absorption peak at $1367 \mathrm{~cm}^{-1}$ could be attributed to the $\mathrm{C}-\mathrm{C}$ stretching of the glucosamine group of chitosan. The absorption peak at $1016 \mathrm{~cm}^{-1}$ is assigned to $\mathrm{C}-\mathrm{O}$ stretching. The characteristic features of the chitosan spectrum observed in the present study are similar to previous reports. ${ }^{21,22}$ FTIR spectra of chitosan-capped gold nanoparticles were assessed to identify the possible interactions between the functional groups of chitosan with gold nanoparticles. When two or more substances are mixed, chemical interactions are reflected by shift or change in the characteristic spectra peaks. ${ }^{22}$ FTIR spectra of chitosan-capped gold nanoparticles in the present study exhibited almost similar peaks as that of pure chitosan, indicating uniform deposition of chitosan over gold nanoparticles. The only difference observed in the FTIR of chitosan-capped AuNP over pure chitosan is the shift of a broad band observed between $3357-3271 \mathrm{~cm}^{-1}$ and $2992-2901 \mathrm{~cm}^{-1}$ and the disappearance of a peak observed at $2856 \mathrm{~cm}^{-1}$. Gold nanoparticles prepared in the present study were stored under frozen conditions to assess the stability in terms of its effective diameter. A slight increase in the size of gold nanoparticles was observed with the storage period for all the three chitosan concentrations (Table 3). However, the increase in the diameter of AuNP with the storage period was not significantly different $(P<0.05)$. The results indicated that storage under constant frozen condition has little influence on the properties of synthesized AuNPs up to 29 days. 
Table 3. Stability of chitosan-capped gold nanoparticles stored under frozen condition

Time (days) Effective diameter $(\mathrm{nm})^{*}$

\begin{tabular}{lccc} 
& Chitosan (0.0625\%) & Chitosan (0.125\%) & Chitosan $(0.25 \%)$ \\
\hline 0 & $175.6 \pm 1.28^{\mathrm{aA}}$ & $59.8 \pm 1.49^{\mathrm{aB}}$ & $30.6 \pm 1.17^{\mathrm{aC}}$ \\
7 & $176 \pm 2.04^{\mathrm{aA}}$ & $62.4 \pm 1.18^{\mathrm{aB}}$ & $30.9 \pm 1.82^{\mathrm{aC}}$ \\
15 & $178.4 \pm 1.67^{\mathrm{aA}}$ & $61.27 \pm 2.04^{\mathrm{aB}}$ & $31.87 \pm 1.08^{\mathrm{aC}}$ \\
21 & $173.86 \pm 2.18^{\mathrm{bA}}$ & $67.54 \pm 1.56^{\mathrm{bB}}$ & $33.76 \pm 1.77^{\mathrm{bC}}$ \\
29 & $180.91 \pm 2.44^{\mathrm{cA}}$ & $60.42 \pm 1.92^{\mathrm{aB}}$ & $34.19 \pm 1.88^{\mathrm{bC}}$ \\
\hline
\end{tabular}

*Mean \pm standard deviation, $n=10$

$A, B, C_{M}$ Mean values in the same row with different letters are significantly different $(P<0.05)$

$a, b, c$ Mean values in the same column with different letters are significantly different $(P<0.05)$

\section{Evaluation of chitosan-capped AuNP as THI}

To assess the effectiveness of chitosan-capped AuNP as THI, the frozen AuNPs prepared from different concentrations of chitosan were exposed to temperature abuse condition $\left(37^{\circ} \mathrm{C}\right)$ from 0 to $48 \mathrm{~h}$ and its UV-Visible spectra and visible color were evaluated. As mentioned in the previous section, $\lambda_{\max }$ was observed at 530 and $540 \mathrm{~nm}$ for $0.125 \%$ and $0.25 \%$ chitosan, respectively, and for lower chitosan concentration, a prominent peak was not observed (Fig. 1a). Upon freezing, peak intensity reduced considerably for AuNPs prepared with $0.125 \%$ chitosan (Fig. 1c). Visible color of AuNPs prepared from higher chitosan concentration $(0.25 \%)$ maintained its cherry red color even after freezing, whereas AuNPs prepared from $0.125 \%$ chitosan concentration lost its bright cherry red color and a grayish color was formed (Fig. 1c). This resulted in feeble peak intensity when observed spectrophotometrically. Lowest chitosan concentration (0.0625\%) did not produce any cherry red-colored AuNPs, but it remained as a light yellow color both before and after freezing. This could be attributed to the higher zeta potential of AuNPs prepared using 0.125 and $0.0625 \%$ chitosan, in which due to higher surface energy, particles got agglomerated and became unstable. Upon exposure to temperature abuse conditions, the peak intensity increased with increase in the period of temperature abuse for AuNPs capped with 0.125 and $0.25 \%$ chitosan concentrations (Fig. 3). However, there was no peak observed for the lowest concentration $(0.0625 \%)$ of chitosan-capped AuNPs up to $24-\mathrm{h}$ abuse period. Although chitosan concentration of $0.125 \%$ exhibited a peak, its intensity was very less compared to $0.25 \%$ chitosan. Chitosan-capped gold nanoparticles prepared from $0.25 \%$ concentration exhibited a clear temperature abuse indicator. UV-vis spectroscopy indicated a shift in the peak to the left with increase in temperature abuse duration (Fig. 3). The initial $\lambda_{\max }$ observed at $540 \mathrm{~nm}$ shifted to $520-524 \mathrm{~nm}$ (blue shift), which could be due to the aggregation of AuNPs upon exposure to temperature-abused conditions. Normally, unaggregated AuNPs will have a red color in solution and turn to blue to purple upon aggregation. Exposure to abused temperature below $4 \mathrm{~h}$ did not show any variations in the peak intensity, which showed a clear difference above $4 \mathrm{~h}$. This indicates that chitosan-capped gold nanoparticles exhibit noticeable differences in the peak intensity when temperature abuse conditions are experienced for $\geq 4 \mathrm{~h}$ under frozen storage. Visible color of chitosan-capped gold nanoparticles also supports the findings of UV-Visible spectra. Only a higher concentration (0.25\%) is effective to be used as an indicator for temperature abuse conditions or THI. Upon exposure from frozen storage to abused temperature, the bright cherry red color began to change with duration of abused temperature. It
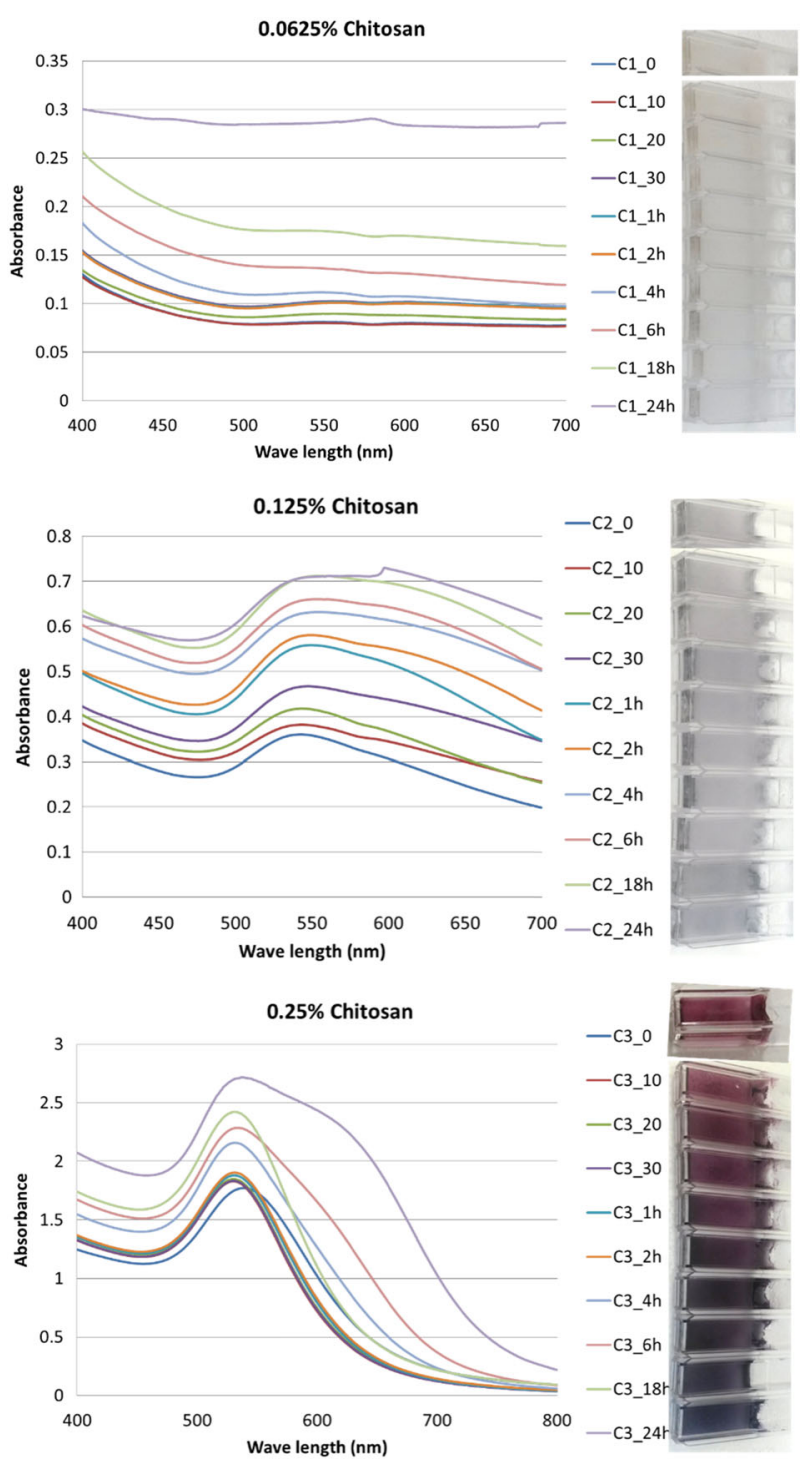

Fig. 3 Effect of temperature abuse on the UV-Visible absorption spectra and the corresponding visible color (inset) of chitosan AuNP at different concentrations $(0.0625,0.125$, and $0.25 \%)$ exposed to different time intervals ( $10 \mathrm{~min}$ to $24 \mathrm{~h}$ )

started to turn purple to dark grayish from $4 \mathrm{~h}$ onward, indicating a clear distinguishing visible color upon temperature abuse of $\geq 4 \mathrm{~h}$. With further increase in temperature abuse period, it turned into a more intense gray color. This could be due to the aggregation of AuNPs and alteration in shape and size upon exposure to time and temperature abuse. Capping with chitosan also alters the absorption and scattering behavior of gold nanoparticles favorable to use as a temperature threshold sensor. In this study, chitosan was used as a reducing and stabilizing agent for the synthesis of gold nanoparticles. During the process, chitosan could quickly adsorb onto the surface of AuNPs, as indicated by FTIR results. As chitosan has a $-\mathrm{NH}_{3}{ }^{+}$group, the chitosan-capped AuNPs are positively charged, which stabilizes AuNPs preventing aggregation even during frozen storage, particularly in $0.25 \%$ chitosan due to a large number of the $-\mathrm{NH}_{3}{ }^{+}$group. When these chitosan-capped AuNPs are exposed to temperature fluctuations, it induces aggregation of chitosancapped AuNPs leading to alteration in the visible color from cherry red to gray. This property was used to design a sensor for temperature abuse indicator. The chitosan-capped AuNP used for 
indicating the temperature abuse conditions during frozen storage is very simple to produce and easy to maintain. It provides reliable irreversible color changes with the temperature abuse and the temperature abuse indicator proposed in this study is disposable type. Very limited quantity $(250-300 \mu \mathrm{L})$ will be sufficient to detect the changes in the chitosan-capped AuNP solution. The developed indicator can be placed onto the pack as labels without coming in contact with the product. However, further study is needed to investigate the mechanism involved in indicating visible color changes of chitosan-capped AuNP during temperature-abused conditions.

\section{CONCLUSION}

Chitosan, a biopolymer of crustacean waste can be used as a reducing agent for the synthesis of gold nanoparticles, which is a greener method. Variation in the concentration of chitosan results in varying the size of AuNPs and exposure to temperature- abused condition resulted in a distinctly different color indicating its efficiency to use as THls. This can be used to ensure the quality and safety of frozen stored perishable food and pharma products during shipment and transportation to distant locations. The preparation method is very simple and ecofriendly and easily adoptable by the industry.

\section{MATERIALS AND METHODS}

Materials

Low-molecular-weight chitosan ( 68,000 Da) procured from Sigma Aldrich Chemicals, USA was used in the study. Hydrogen tetrachloroaurate (III) trihydrate $\left(\mathrm{HAuCl}_{4} \cdot 3 \mathrm{H}_{2} \mathrm{O}\right)$ was from Acros Chemicals (New Jersey, USA), whereas glacial acetic acid for the preparation of chitosan solution was procured from Fisher Scientific, USA.

\section{Methods}

Properties of chitosan. Chitosan used in the study was analyzed for sensory appearance to assess its color. Moisture content was determined by drying a known amount of sample to constant weight in an air oven at $105 \pm 2^{\circ} \mathrm{C}$ for $16 \mathrm{~h}^{23}$ The percentage of crude protein was determined by the total nitrogen method. ${ }^{23}$ Ash content was determined by heating at $550 \pm 2{ }^{\circ} \mathrm{C}$ in a muffle furnace. ${ }^{23}$ The degree of deacetylation of the chitosan was determined following the method of Shigemassa et al. ${ }^{24}$ The $\mathrm{pH}$ measurements of the chitosan solutions ( $1 \% \mathrm{w} / \mathrm{v}$, in acetic acid) were carried out using a glass electrode digital pH meter (Cyberscan 510, Eutech Instruments, Singapore). ${ }^{25}$ Viscosity of chitosan solutions was determined at room temperature by using a digital viscometer (Brookfield DV-E Viscometer, Middleboro, MA) and values were expressed as centipoise (cP).

Optimization of conditions for synthesis of chitosan-AuNP and its characterization. Chitosan concentration $(0.0625,0.125$, and $0.25 \%)$ heating temperature $\left(70,80\right.$, and $\left.90^{\circ} \mathrm{C}\right)$, and heating duration $(5,10$, and $15 \mathrm{~min}$ ) were used for optimization of synthesizing chitosan-capped AuNPs. For this, different concentrations of chitosan dissolved in 1\% acetic acid were exposed to $90^{\circ} \mathrm{C}$ maintained in a stirring water bath (Major Science, USA) for $30 \mathrm{~min}$ to dissolve the chitosan completely. To this, $5 \mathrm{~mL}$ of $10 \mathrm{mM} \mathrm{HAuCl}{ }_{4} \cdot 3 \mathrm{H}_{2} \mathrm{O}$ was added with continuous stirring and continued heating in the water bath maintaining different temperatures $(70,80$, and $\left.90^{\circ} \mathrm{C}\right)$. The color evolution was observed for all the samples for different time intervals $(5,10$, and $15 \mathrm{~min})$. After this time interval, the samples were removed from the water bath and cooled immediately to room temperature using running water. Upon cooling, spectroscopic absorption $(400-700 \mathrm{~nm})$ of chitosan-capped AuNPs was measured using a UV -Visible spectrophotometer (Lambda 25, Perkin Elmer, USA). The colloidal chitosan-capped gold nanoparticles were directly used without any dispersing agents/diluents. The effect of chitosan concentrations on the size of the AuNPs, zeta potential, and polydispersity were assessed using a particle size analyzer (90 Plus Particle Size Analyser, Brookhaven Instruments Corporation, USA). In this, colloidal chitosan-capped gold nanoparticles were directly used without any dispersing agents. Disposable plastic cells are used for the analysis. Around $1.5 \mathrm{~mL}$ of chitosancapped gold nanoparticles solution was added to the measuring cell and
PTFE stoppers were used. Size distribution was measured by the dynamic light-scattering method using a particle size analyzer equipped with a Peltier temperature control system. Measurements were conducted at a fixed angle of $90^{\circ}$ and a wavelength of $659 \mathrm{~nm}$. Five replicate measurements were performed for each experimental condition. Each measurement consisted of five subsequent individual runs of $30 \mathrm{~s}$ duration. Fourier transform-infrared spectroscopy of pure chitosan and chitosancapped AuNPs was performed using attenuated total reflectance-Fourier transform-infrared (ATR-FTIR) spectrophotometer (Spectrum 100, Perkin Elmer, USA). The stability of the AuNPs prepared using different concentrations of chitosan was assessed in the frozen storage conditions. For this, the frozen stored cuvettes containing chitosan-capped AuNPs were removed at regular intervals $(0,7,15,21$, and 29 days) and thawed in the water bath (Thermomix 1420, USA) maintained at $37^{\circ} \mathrm{C}$ and used for assessing the stability in terms of its size. After selecting the suitable concentration of chitosan initially, the concentration of chitosan was further optimized by varying chitosan concentration by $\pm 0.05 \%$.

Evaluation of chitosan-capped AuNPs as an indicator for monitoring frozen temperature abuse condition. Chitosan-capped gold nanoparticles were assessed for their temperature threshold sensing properties. For this, different chitosan concentrations $(0.0625,0.125$, and $0.25 \% \mathrm{w} / \mathrm{v})$, time $(15 \mathrm{~min})$, and temperature $\left(90^{\circ} \mathrm{C}\right)$ were used to prepare chitosan-capped AuNPs. The chitosan-capped gold nanoparticles colloidal solution was poured into $1.5-\mathrm{mL}$ semi-micro disposable cuvettes (PMMA, Brandtech Scientific Inc., USA) and kept at a temperature of $-18^{\circ} \mathrm{C}$ for $6-7$ days to freeze the solution. To simulate temperature abuse for frozen stored products, the cuvettes containing colloidal gold nanoparticles solution were exposed to higher temperature $\left(\sim 37^{\circ} \mathrm{C}\right)$ for varying duration (10 min to $48 \mathrm{~h}$ ). After this, the cuvettes containing gold nanoparticles solution were replaced back to a frozen store and allowed to stabilize for 4 days. The variations in the visible color as well as UV-Visible spectrophotometer spectra upon exposure to temperature abuse were recorded and compared with the initial frozen sample. The visible color variations obtained for gold nanoparticles upon temperature abuse indicating its application for temperature threshold sensor were evaluated.

\section{Statistical analysis}

The results are expressed as mean \pm standard deviation. Experimental data were analyzed using the software SPSS version $10.00{ }^{26}$ For data analysis, mean, standard deviation, and analysis of variance were used. Significance of differences was defined at $P<0.05$.

\section{DATA AVAILABILITY}

The authors declare that the data supporting the findings of this study are available with the authors.

\section{ACKNOWLEDGEMENTS}

C.O.M. would like to thank Indian Council of Agricultural Research, New Delhi, India for financial support under NAIP for International Training Program from World Bank. The support and encouragement given by Dr. Srinivasa Gopal, former director, ICARCentral Institute of Fisheries Technology, Cochin, India in accomplishing this work and for permission to publish this work by present director, ICAR-CIFT is also acknowledged by the first author. Special thanks to Dr. Y.-C. Wang, research scholar (former) of Biological Systems Engineering Department, University of WisconsinMadison, USA for all the help and support in executing this study. The support and help rendered by the scholars and staffs of Biological Systems Engineering Department, University of Wisconsin-Madison, USA is acknowledged. The support and encouragement received from the family members and ICAR-CIFT is greatly acknowledged by the first author.

\section{AUTHOR CONTRIBUTIONS}

C.O.M.: Conceptualized, planned, analyzed and executed the work, and wrote the article. S.G.: Conceptualized, designed, and facilitated the work. Helped in writing the article, corrected, and approved the final version. C.N.R.: Facilitated the work and corrected the article.

\section{ADDITIONAL INFORMATION}

Competing interests: The authors declare no competing interests. 
Publisher's note: Springer Nature remains neutral with regard to jurisdictional claims in published maps and institutional affiliations.

\section{REFERENCES}

1. Singh, R. P. D. in Shelf Life Evaluation of Food 2nd edn (eds Man, C. M. D. \& Jones, A.), 3-22 (Aspen Publishers, Gaithersburg, MD, 2000).

2. Bagci, P. O., Wang, Y. C. \& Gunasekaran, S. A simple and green route for roomtemperature synthesis of gold nanoparticles and selective colorimetric detection of cysteine. J. Food Sci. 80, N2071-N2078 (2015).

3. Mohanpuria, P., Rana, N. K. \& Yadav, S. K. Biosynthesis of nanoparticles: technological concepts and future applications. Nanopart. Res. 10, 507-517 (2008).

4. Mohan, C. O., Ravishankar, C. N., Lalitha, K. V. \& SrinivasaGopal, T. K. Effect of chitosan edible coating on the quality of double filleted Indian oil sardine (Sardinella longiceps) during chilled storage. Food Hydrocoll. 26, 167-174 (2012).

5. Ng, C. H., Hein, S., Ogawa, K., Chandrkrachang, S. \& Stevens, W. F. Distribution of D-glucosamine moieties in heterogeneously deacetylated cuttlefish chitin. Carbohyd Polym. 69, 382-390 (2007).

6. Remya, S. et al. Effect of chitosan based active packaging film on the keeping quality of chilled stored barracuda fish. J. Food Sci. Technol. 53, 685-693 (2016).

7. Remya, S., Mohan, C. O., Venkateswarlu, G., Sivaraman, G. K. \& Ravishankar, C. N. Combined effect of $\mathrm{O}_{2}$ scavenger and antimicrobial film on shelf life of fresh cobia (Rachycentron canadum) fish steaks stored at $2^{\circ} \mathrm{C}$. Food Cont. 71, 71-78 (2017).

8. Renuka, V., Mohan, C. O., Kriplani, Y., Sivaraman, G. K. \& Ravishankar, C. N. Effect of chitosan edible coating on the microbial quality of Ribbonfish, Lepturacanthussavala (Cuvier, 1929) steaks. Fish. Technol. 53, 146-150 (2016).

9. Huang, H. \& Yang, X. Synthesis of chitosan-stabilized gold nanoparticles in the absence/presence of tripolyphosphate. Biomacromolecules 5, 2430-2346 (2004).

10. Wang, B. et al. Chitosan-mediated synthesis of gold nanoparticles on patterned poly (dimethylsiloxane) surfaces. Biomacromolecules 7, 1203-1209 (2006).

11. Chen, Z., Wang, Z., Chen, X., Xu, H. \& Liu, J. Chitosan-capped gold nanoparticles for selective and colorimetric sensing of heparin. J. Nanopart. Res. 15, 1930-1939 (2013).

12. Yang, N. \& Li, W. Preparation of gold nanoparticles using chitosan oligosaccharide as a reducing and capping reagent and their in-vitro cytotoxic effect on human fibroblast cells. Mater. Lett. 138, 154-157 (2015).

13. Boyles, M. S. P. et al. Chitosan functionalization of gold nanoparticles encourages particle uptake and induces cytotoxicity and pro-inflammatory conditions in phagocytic cells, as well as enhancing particle interactions with serum components. J. Nanobiotechnol. 13, 84-104 (2015).

14. Wang, Y. C., Lin, L. \& Gunasekaran, S. Biopolymer/gold nanoparticles composite plasmonic thermal history indicator to monitor quality and safety of perishable bioproducts. Biosens. Bioelectron. 92, 109-116 (2017).
15. Wang, Y. C., Lin, L. \& Gunasekaran, S. Gold nanoparticle-based thermal history indicator for monitoring low-temperature storage. Microchim. Acta 182, 1305-1311 (2015).

16. Li, Q. D., Dunn, E. T., Grandmaison, E. W. \& Goosen, M. F. A. Applications and properties of chitosan. J. Bioact. Compat. Pol. 7, 370-397 (1992).

17. Wang, Y. C. \& Gunasekaran, S. Spectroscopic and microscopic investigation of gold nanoparticle nucleation and growth mechanisms using gelatin as a stabilizer. J. Nanopart. Res. 14, 1-11 (2012).

18. Adlim, A. \& Bakar, M. A. Preparation of chitosan-gold nanoparticles: Part 2. The role of chitosan. Indones. J. Chem. 8, 320-326 (2008).

19. Marchessault, R. H., Ravenelle, F. \& Zhu, X. X. Polysaccharides for Drug Delivery and Pharmaceutical Applications (American Chemical Society, New York, 2006).

20. Mano, J. F., Koniarova, D. \& Reis, R. L. Thermal properties of thermoplastic starch/ synthetic polymer blends with potential biomedical applicability. J. Mat. Sci. Mat. Med. 14, 127-135 (2003).

21. Nunthanid, J., Puttipipatkhachorn, S., Yamamoto, K. \& Peck, G. E. Physical properties and molecular behavior of chitosan films. Drug Dev. Ind. Pharm. 27, 143-147 (2001).

22. Xu, Y., Kim, K., Hanna, M. \& Nag, D. Chitosan-starch composite film: preparation and characterization. Ind. Crop. Prod. 21, 185-192 (2005).

23. AOAC. Official Methods of Analysis, 17th edn, Vol. II, 1-27 (Maryland, USA, 2000).

24. Shigemassa, Y., Matsuura, H. \& Sashiwa, H. Evaluation of different absorbance ratios from infrared spectroscopy for analyzing the degree of deacetylation in chitin. Int. J. Biol. Macromol. 18, 237-242 (1996).

25. IS: 2168. Specification for Pomfret Canned in Oil (Indian Standard Institute, New Delhi, India, 1971).

26. SPSS. Statistical Software Package for Social Sciences for Windows-Release 10 (SPSS, Chicago, IL, 2000).

(c) Open Access This article is licensed under a Creative Commons Attribution 4.0 International License, which permits use, sharing, adaptation, distribution and reproduction in any medium or format, as long as you give appropriate credit to the original author(s) and the source, provide a link to the Creative Commons license, and indicate if changes were made. The images or other third party material in this article are included in the article's Creative Commons license, unless indicated otherwise in a credit line to the material. If material is not included in the article's Creative Commons license and your intended use is not permitted by statutory regulation or exceeds the permitted use, you will need to obtain permission directly from the copyright holder. To view a copy of this license, visit http://creativecommons. org/licenses/by/4.0\%.

(c) The Author(s) 2019 